\title{
Tannic Acid Alleviates Lipopolysaccharide-Induced H9C2 Cell Apoptosis by Suppressing ROS-Mediated ER Stress
}

\section{Yanping Yang}

Air Force Medical University

Jieqiong Zhao

Air Force Medical University Tangdu Hospital

Haibo Gao

Air Force Medical University Tangdu Hospital

Runze Wang

Air Force Medical University Tangdu Hospital

Jinjing Li

Air Force Medical University Tangdu Hospital

Xiaoli Li

Air Force Medical University Tangdu Hospital

Xiaolin Niu

Air Force Medical University Tangdu Hospital

Yonghong Lei

Chinese PLA General Hospital

Xue Li ( $\sim$ lxhlms@126.com )

Air Force Medical University https://orcid.org/0000-0002-4307-6684

\section{Research}

Keywords: Tannic acid, Lipopolysaccharide, Reactive oxygen species, ER stress, Apoptosis

Posted Date: January 21st, 2021

DOl: https://doi.org/10.21203/rs.3.rs-150803/v1

License: (c) (i) This work is licensed under a Creative Commons Attribution 4.0 International License.

Read Full License 


\section{Abstract}

Background: Sepsis-induced myocardial dysfunction (SIMD), which is one of the features of multiple organ dysfunction in sepsis with extremely high mortality, is characterized by impaired myocardial compliance. To date, there are few effective treatment options to cure sepsis. Tannic acid (TA) is reportedly protective during sepsis. However, the underlying mechanisms by which TA protects against septic heart injury remains elusive.

Methods: We investigated the potential effects and underlying mechanisms of TA in alleviating lipopolysaccharide (LPS)-induced H9C2 cardiomyocyte cell apoptosis. H9C2 cells were treated with LPS $(15 \mu \mathrm{g} / \mathrm{mL}), \mathrm{TA}(10 \mu \mathrm{M})$ and TA+LPS. Control cells were treated with media only. Apoptosis was measured using flow cytometry, RT-PCR, and Western blotting analysis. Additionally, laser confocal immunofluorescence analysis detected the production of reactive oxygen species (ROS). Western blot and RT-PCR were employed to detect ER stress-associated functional proteins.

Results: The results demonstrated that TA reduced the degree of LPS-induced H9C2 cells injury, including the inhibition of ROS production and endoplasmic reticulum (ER) stress-associated apoptosis. ER stressassociated functional proteins, including ATF6, PERK, IRE1, XBP1s, and CHOP were suppressed in response to TA treatment. Furthermore, the expression levels of ER stress-associated apoptotic proteins, including JNK, Bax, Cyt, Caspase3, Caspase12, and Caspase9 were reduced following treatment with TA. Additionally, the protective effects of TA on LPS-induced H9C2 cells were strengthened following treatment with the ROS inhibitor, N-Acetylcysteine (NAC), which demonstrated that ROS-mediated ER stress-associated apoptosis and TA decreased ROS-mediated ER stress-associated apoptosis.

Conclusion: Our findings demonstrated that the protective effects of TA against LPS-induced H9C2 cells apoptosis may be associated with the amelioration of ROS-mediated ER stress. These findings may assist the development of potential novel therapeutic methods to inhibit the progression of myocardial cell injury. (TA alleviates LPS-induced $\mathrm{H} 9 \mathrm{C} 2$ cell apoptosis.)

\section{Introduction}

Sepsis is a life-threatening multiple organ dysfunction syndrome (MODS) characterized by a disordered immune, endocrine, and metabolic response to infection [1,2]. Severe sepsis may result in significant morbidity and mortality [3-6]. Myocardial dysfunctions are common among patients with severe sepsis. Cardiac dysfunction is a well-recognized feature of MODS [7, 8]. Sepsis-induced myocardial dysfunction (SIMD) was identified as a sepsis-associated acute syndrome of cardiac dysfunction. Many factors, such as lipopolysaccharide (LPS), tumor necrosis factor-alpha (TNF-a) and IL-1 are associated with SIMD [9, 10]. Several mechanisms have been proposed to explain the pathophysiology of SIMD, including excessive generation of inflammatory cytokines, reactive oxygen species (ROS) or nitrogen radicals, as well as transcriptional and compromised metabolic changes [11-14]. Despite extensive studies, the relevant pathogenesis of SIMD has not yet been clearly defined to date $[13,14]$. 
LPS is a component of the outer membrane of Gram-negative bacteremia, it has been regarded as the principal cause responsible for cardiac dysfunction in sepsis [15]. LPS associates with its receptor, tolllike receptor 4, to stimulate the production of inflammatory cytokines and simultaneously generate abundant ROS, which might directly disturb cardiac function $[13,14]$. ROS are by-products of normal cellular oxidative processes, and are generated in response to external stimuli such as inflammatory cytokines including LPS, chemotherapeutic drugs, and ionizing radiation $[16,17]$. Excessive ROS, which is considered to be a marker of oxidative stress, causes cell apoptosis [18]. Enhancing the cellular antioxidant capacity or ROS-scavenging activity may act to ameliorate the imbalance in a variety of pathologies and disease models $[14,16]$. Excessive ROS production can trigger endoplasmic reticulum (ER) stress, which is called ROS-mediated ER stress [19]. Endoplasmic reticulum stress (ERS) is one of the mechanisms contributing to ROS-mediated cell apoptosis [20], and ERS-associated cardiomyocyte apoptosis is a major contributor to myocardial injury [21]. The ER organelle is responsible for the folding of secretory and membrane proteins. In mammals, the ERS response is mediated by three known transmembrane sensor proteins in the endoplasmic reticulum, namely the inositol requiring enzyme 1 (IRE1), activating transcription factor 6 (ATF6) and protein kinase-like endoplasmic reticulum kinase (PERK). Numerous intracellular and extracellular stimuli can cause the accumulation of unfolded and misfolded proteins, resulting in the dissociation of glucose-regulated protein 78 (GRP78) from the three ER transmembrane protein sensors PERK, ATF6 and IRE1, and subsequently trigger the unfolded protein response (UPR) [22]. If the stimulus is serious and/or lengthy, it can activate ER stress-related C/EBPhomologous protein (CHOP), caspase-12, and/or JNK-dependent apoptotic signaling pathways [23, 24]. Attenuation of ER stress with pharmacological or gene therapy strategies has been successful in reducing pathological features in various experimental models of inflammatory diseases, including sepsis $[25,26]$. Therefore, SIMD may be alleviated by the regulation of ROS and ERS. There is urgent need for innovative therapeutic options for the treatment of SIMD, which is essential for decreasing mortality from sepsis.

Tannic acid (TA), a specific type of tannin, is water-soluble polyphenols with a $\mathrm{C}_{76} \mathrm{H}_{52} \mathrm{O}_{46}$ chemical structure, and is a mixture of five galloyl esters and one glucose [27]. Previous studies have indicated that TA possesses anticarcinogenic, antioxidant, antimutagenic, anti-inflammatory, antifibrotic, and cardioprotective effects [28-32]. To date, there are no published scientific reports on the effects of TA on LPS-induced myocardial injury or related ailments. Whether ERS regulates the inhibitory effects of TA during LPS-induced myocardial dysfunction remains unknown. Additionally, the specific mechanism by which TA alleviates myocardial dysfunction urgently needs to be investigated. Therefore, in this study we aimed to identify the role of TA in LPS-induced cardiomyocytes injury, and to elucidate the underlying mechanisms using $\mathrm{H} 9 \mathrm{C} 2$ cells.

\section{Materials And Methods}

\section{Materials}


Tannic acid (TA) (catalog number T0801) was purchased from Topscience (Shanghai, China). NAcetylcysteine (NAC) (catalog number HY-B0215) was purchased from Med Chem Express (Monmouth Junction, NJ,USA). LPS (Lipopolysaccharide from Escherichia coli 055:B5) was purchased from Sigma Aldrich (St. Louis, MO, USA), and the rat heart myoblast cell line H9C2(2-1) (catalog number GNR 5) was obtained from the Cell Bank of the Chinese Academy of Sciences (Shanghai, China). High-glucose DMEM (catalog number 12800017) was purchased from GIBCO BRL (Grand Island, NY, USA). Phosphatebuffered saline (PBS) (catalog number SH30256.01) and trypsin (catalog number SH30042.01) were purchased from GE Healthcare (Logan, UT, USA). Pierce ${ }^{\mathrm{Tm}}$ BCA Protein Assay Kit (catalog number 23227) and fetal bovine serum (FBS) (catalog number 10270106) were obtained from Thermo Fisher Scientific (Waltham, MA, USA). ROS assay kit was purchased from Nan jing Jian cheng Bioengineering Institute (Nanjing, China). Cell Counting Kit-8 assay (CCK-8) was purchased from 7sea biotech (Shanghai, China). Culture dishes (catalog numbers 430166 and 430167) were purchased from Corning Costar Company (Cambridge, MA, USA).

\section{Antibodies}

Primary antibody directed against GAPDH (catalog number ab9485) was purchased from Abcam (Cambridge, MA, USA); primary antibodies against Cleaved Caspase 3 (catalog number BF0711), Cleaved Caspase 9 (catalog number AF5240), Bax (catalog number AF0120), Bcl-2 (catalog number AF6139), ATF6 (catalog number DF6009), CHOP (catalog number DF6025), Phospho-PERK (catalog number DF7576), PERK (catalog number AF4799), Phospho-IRE1 (catalog number AF7150), IRE1 (catalog number DF7709), Phospho-JNK (catalog number AF3318) and JNK (catalog number AF6318) were obtained from Affinity (Cincinnati, OH, USA). HRP-conjugated secondary antibodies (catalog numbers ab6721 and ab6885) and a FITC-conjugated secondary antibody (catalog number ab6717) were purchased from Abcam (Cambridge, MA, USA).

\section{Cell culture and treatment}

The $\mathrm{H} 9 \mathrm{C} 2$ cells were cultured in high-glucose DMEM supplemented containing $10 \%(\mathrm{v} / \mathrm{v}) \mathrm{FBS}, 1.5 \mathrm{~g} / \mathrm{L}$ $\mathrm{NaHCO}_{3}$ and $1 \%$ penicillin-streptomycin (Life Technologies Corporation, Carlsbad, CA, USA) at $37^{\circ} \mathrm{C}$ in a humidified atmosphere with $5 \% \mathrm{CO}_{2}$, and maintained in a logarithmic growth phase for all experiments. $\mathrm{H} 9 \mathrm{C} 2$ cells were treated with LPS $(15 \mu \mathrm{g} / \mathrm{mL})$ for $12 \mathrm{~h}$, and different concentrations of TA $(0,5,10,20,30$, and $40 \mu \mathrm{M}$ ) for $24 \mathrm{~h}$. H9C2 cells were pretreated with TA $2 \mathrm{~h}$ prior to treatment with LPS. For ROS inhibition experiments, inhibitor N-Acetylcysteine (NAC; $2 \mathrm{mM}$ ) was added prior to TA. Then $8 \mathrm{~h}$ later, and cells were harvested for further analysis.

\section{CCK-8 assay}


The H9C2 cells were seeded in 96-well plate at a density of 5000 cells/well, and treated with the following conditions: fresh culture medium alone (control), fresh culture medium with different concentrations (0$50 \mu \mathrm{M}$ ) of TA, and/or fresh culture medium with $15 \mu \mathrm{g} / \mathrm{mL}$ LPS for the indicated times. Cell viability was assessed using the cell counting kit, CCK-8, according to manufacturer's instructions. Briefly, after treatment, the CCK-8 solution $(10 \mu \mathrm{L})$ was added to each well and the cultures were incubated at $37^{\circ} \mathrm{C}$ in humidified $95 \%$ air and $5 \% \mathrm{CO}_{2}$ for $1 \mathrm{~h}$. Absorbance was measured at $450 \mathrm{~nm}$ using a Microplate Reader (Bio-Rad, Hercules, CA). Values were expressed as the percentage of viable cells as follows: Relative viability $(\%)=[O D 450$ (treated) - OD450 (blank)] / [OD450 (control) - OD450 (blank)] × 100\%.

\section{Measurement of cellular ROS by laser confocal microscopy}

The cellular ROS Detection Assay Kit contains the fluorogenic dye, 2,7-dichlorofluorescin-diacetate (DCFDA), that measures ROS activity within the cell. After diffusion into the cell, DCFDA is deacetylated by cellular esterases to a non-fluorescent compound, which is later oxidized by ROS into 2', 7'dichlorofluorescein (DCF). DCF is a highly fluorescent compound which can be detected by fluorescence spectroscopy with excitation / emission at $485 \mathrm{~nm} / 535 \mathrm{~nm}$. The H9C2 cells were incubated with 2,7dichlorofluorescein-diacetate (DCFH-DA, $10 \mu \mathrm{M}$, Jian cheng, China) for $30 \mathrm{~min}$ at $37^{\circ} \mathrm{C}$ in the dark. The cells were subsequently washed twice with PBS and observed under a confocal laser scanning microscope (Leica), and the images were captured. The mean fluorescence intensity of DCF was analyzed.

\section{Flow cytometric analysis of apoptosis}

Fluorescein-conjugated annexin V (annexin V-FITC) was used to measure the apoptosis in H9C2 cells as described previously [33]. The necrotic cells were counter stained with propidium iodide (PI). Cells were plated in 60-mm dishes and exposed to different treatments once reaching 80-85\% confluence. Detached and adherent cells were collected, washed twice with cold PBS, and then resuspended in the $1 \mathrm{X}$ binding buffer at a concentration of $1 \times 10^{6}$ cells $/ \mathrm{mL}$. The resuspended solution containing $1 \times 10^{5}$ cells $(100 \mu \mathrm{L})$ was transferred to a $5 \mathrm{~mL}$ culture tube, to which $5 \mu \mathrm{L}$ of FITC Annexin $\mathrm{V}$ and $5 \mu \mathrm{L}$ PI were added, and gently vortexed, prior to $15 \mathrm{~min}$ incubation at $25^{\circ} \mathrm{C}$ in the dark. Binding buffer $1 \mathrm{X}(400 \mu \mathrm{L})$ was added to each tube, and the percentages of apoptotic cells were analyzed by flow cytometry within $1 \mathrm{~h}$.

\section{RT-PCR}

Real-time quantitative polymerase chain reaction (RT-PCR) analysis was performed as described previously [34]. The primer sequences are described in Table 1. Briefly, total RNA was extracted using Trizol (catalog number 15596026, Life technologies, California, USA), and then DNase was used to remove internal DNA contamination. Random primers were used in reverse transcription reactions to obtain first-strand cDNA, and SYBR Green qPCR Master Mix (catalog number FP202, Tiangen, Beijing, 
China) was used to amplify the target fragments. GAPDH cDNA amplification was used as an internal control. The general reaction procedure included an initial denaturing step at $95^{\circ} \mathrm{C}$ for 15 minutes followed by 37 cycles of denaturing at $95^{\circ} \mathrm{C}$ for $10 \mathrm{sec}$, annealing at $57^{\circ} \mathrm{C}$ for $30 \mathrm{sec}$, and extension at 72 ${ }^{\circ} \mathrm{C}$ for $30 \mathrm{sec}$, with a plate read at $95^{\circ} \mathrm{C}$ for $5 \mathrm{sec}$. Each experimental group was performed in triplicate. IBM SPSS (version 19) software was used to analyze differences in expression.

\section{Western blotting}

Western blotting was performed as describing previously [35]. Briefly, cells were lysed in lysis buffer containing $50 \mathrm{mM}$ Tris- $\mathrm{HCl}$ (pH 7.4), $150 \mathrm{mM} \mathrm{NaCl}, 1 \mathrm{mM}$ EDTA, $0.25 \%$ sodium deoxycholate, and 1\% NP40 with a protease inhibitor cocktail and phosphatase inhibitor cocktail, The insoluble components were removed by centrifugation at $12,000 \times \mathrm{g}$ for 15 minutes at $4{ }^{\circ} \mathrm{C}$. Subsequently, protein concentrations were measured using the BCA method. After denaturation, the total proteins were separated by $10 \%$ SDSPAGE and transferred onto $0.2 \mu \mathrm{m}$ or $0.45 \mu \mathrm{m}$ polyvinylidene fluoride membranes. After blocking with $5 \%$ $(\mathrm{w} / \mathrm{v})$ non-fat milk for $2 \mathrm{~h}$ at room temperature, the membranes were incubated with primary antibodies diluted in blocking buffer overnight at $4{ }^{\circ} \mathrm{C}$. The membranes were subsequently washed three times with $1 \times$ TBST, and further incubated with HRP-conjugated secondary antibodies for $2 \mathrm{~h}$ at room temperature. After subsequent washes of the membrane, three times with $1 \times$ TBST, antibody detection was performed using the Immobilon Western Chemiluminescent HRP Substrate (ECL, catalog number WBKLS0500, Merck Millipore, MA, USA) and the detection kit using a ChemiDoc ${ }^{T M}$ XRS + system (Bio-Rad, Hercules, California, USA). ImageJ (version 1.46) was used to compare the gray values of the target bands; GAPDH served as an internal control.

\section{Statistical analysis}

Data is presented as the mean \pm standard error of the mean (SEM) from at three independent experiments. GraphPad Prism 8.0.2 (GraphPad Software Inc., La Jolla, CA) was used for statistical analysis. Statistical significance was determined by one-way ANOVA with Bonferroni correction for multiple comparisons. A P value $<0.05$ was considered statistically significant. The number of independent experiments performed is indicated in the figure legends.

\section{Results}

\section{Effect of TA on LPS-induced cell viability of $\mathrm{H} 9 \mathrm{C} 2$ cells.}

Prior to investigating whether TA protected $\mathrm{H} 9 \mathrm{C} 2$ cells from LPS-induced cell injury, the cytotoxicity of the extract was determined by culturing $\mathrm{H} 9 \mathrm{C} 2$ cells until reaching $80-90 \%$ confluence in 96 -well plates, and treating them with different dosages of TA $(0,5,10,20,30,40$ and $50 \mu \mathrm{M})$ for $24 \mathrm{~h}$. Cell viability assessment, using the CCK-8 assay, appeared to reveal slightly increased cell viability at TA concentrations less than $10 \mu \mathrm{M}$; however, these increases were not statistically significant when 
compared to the control group (Fig. 1a). Following treatment of $\mathrm{H} 9 \mathrm{C} 2$ cells with TA concentrations greater than $30 \mu \mathrm{M}$, the cell viability significantly decreased. Thus, to exclude cell toxicity, concentrations of 5,10 , and $20 \mu \mathrm{M}$ were selected for subsequent experiments. To examine the effects of TA on LPS-induced cell injury, the viability of $\mathrm{H} 9 \mathrm{C} 2$ cells pretreated with $0,5,10$ and $20 \mu \mathrm{M} \mathrm{TA}$, and then treated with $15 \mu \mathrm{g} / \mathrm{mL}$ LPS was determined. As shown in Fig. 1b, LPS treatment significantly diminished cell viability to $50.65 \pm$ $0.5 \%$ compared to control. Interestingly, pretreatment with TA $(5,10$ and $20 \mu \mathrm{M})$ prior to the LPS treatment significantly improved cell viability to $68.3 \pm 0.8 \%, 84.6 \pm 2.1 \%$ and $90.6 \pm 3.3 \%$, respectively, compared to control. Our findings demonstrated that pretreatment with TA dose-dependently increased the cell viability diminished by the LPS treatment, and suggested that TA is capable of protecting H9C2 cells from LPSinduced cell injury.

\section{TA alleviates LPS-induced apoptosis in $\mathrm{H} 9 \mathrm{C} 2$ cells.}

To further evaluate the effect of TA on LPS-induced apoptosis, H9C2 cells were treated either with LPS or a combination of TA and LPS. Cell apoptosis was measured by flow cytometry, and the expression of apoptosis-associated proteins in the $\mathrm{H} 9 \mathrm{C} 2$ cells was measured by western blotting. As presented in Fig. $2 \mathrm{a}$ and $2 \mathrm{~b}$, the percentage of apoptotic cells significantly increased after LPS treatment. Whereas, pretreatment with TA significantly decreased the percentage of apoptotic cells induced by the LPS treatment. Consistent with the flow cytometric results, LPS increased the protein expression of apoptotic markers Bax/Bcl2, Cleaved Caspase3 and Cleaved Caspase9, compared to the control group. However, pretreatment with TA decreased the expression of these markers compared to treatment with LPS alone (Fig. 2c and 2d). Notably, the detected levels of all markers in the TA-only group were comparable to the control (medium) treatment. Our results suggested that TA alleviated LPS-induced H9C2 cells apoptosis.

\section{TA attenuates ROS generation in LPS-induced H9C2 cells.}

The level of ROS is a crucial index of oxidative stress. To further evaluate the effects of TA on LPSinduced oxidative stress, the level of intracellular ROS was monitored by detecting changes in DCF fluorescence by laser confocal microscopy. As shown in Fig. 3a and 3b, LPS treatment significantly elevated ROS generation to level of the control group treated with cultural medium. However, the LPSmediated increase in DCF fluorescence was significantly decreased with TA pretreatment. Notably, the ROS levels detected in the TA-only treated group was comparable to the control group treated with medium only, demonstrating the minimum cell toxicity of this chosen TA dose. Our results suggested that TA was capable of reducing intracellular ROS accumulation following LPS stimulation. The ability of TA to inhibit intracellular ROS production contributed to the efficacy at protecting the $\mathrm{H} 9 \mathrm{C} 2$ cells against LPS-induced apoptosis.

\section{TA alleviates LPS-induced ER stress in $\mathrm{H} 9 \mathrm{C} 2$ cells.}

To determine the effect of TA on ERstress in H9C2 cells induced by LPS, the expression of ER stressassociated proteins was examined. As presented in Fig. 4a-C, the expression of ER stressassociated proteins proapoptotic CHOP, ATF6, Phospho-PERK, PERK, Phospho-IRE1/IRE1 were significantly increased 
after exposure to LPS compared to the control group. Additionally, the expression of ER stressassociated proteins were markedly downregulated in the TA and LPS group compared to the group treated with LPS only. This result suggested that pretreatment with TA significantly downregulated the expression of ER stressassociated proteins, which alleviated LPS-induced ER stress. Based on this finding, it is feasible to hypothesize that the ER stressassociated proteins proapoptotic CHOP, ATF6, PERK and IRE1 maybe underlying players involved in alleviating LPS-induced H9C2 cell apoptosis by TA.

\section{TA attenuated LPS-induced apoptosis by suppressing ROS-mediated ER stress in H9C2 cells.}

We further examined the protective effects of TA on $\mathrm{H} 9 \mathrm{C} 2$ cells and explored the relationship between ROS and ER stress-associated apoptosis in LPS-induced H9C2 cells. To determine whether LPS-induced ROS modulated ER stress in $\mathrm{H} 9 \mathrm{C} 2$ cells we used the ROS scavenger, NAC, to evaluate the relationships between ROS, ERS, and apoptosis. As presented in Fig. 5a-c and 5i-k, H9C2 cells were pretreated with NAC $1 \mathrm{mM}$ or TA $10 \mu \mathrm{M}$, and then co-treated with LPS $15 \mu \mathrm{g} / \mathrm{mL}$. The protein expression levels of ER stressassociated proteins (CHOP, ATF6, Phospho-PERK, PERK, Phospho-IRE1, and IRE1) and apoptosisassociated proteins ( $\mathrm{p}-\mathrm{JNK}$, JNK, Cleaved Caspase3, Bax/Bcl-2, and Cleaved Caspase9) were detected by western blotting. The detected mRNA expression levels of ER stressassociated genes (Chop, Atf6, Perk, Ire1, and Xbp1s) and apoptosis-associated genes (Bax, Caspase3, Caspase12, and Cyt) are described in Fig. $5 \mathrm{~d}$-h and $5 \mathrm{l}$-o. LPS caused a significant increase in the expression of ER stressassociated proteins and apoptosis-associated proteins; however, these protein levels were markedly decreased after TA or NAC pretreatment. Moreover, The expression of ER stressassociated proteins and apoptosis-associated proteins couldn't be inhibited by TA in the presence of ROS inhibitors such as NAC. The levels of all markers detected in the NAC-only group were similar to that observed in the medium control treatment group. Our results indicated that ER stress activation and apoptosis activation were inhibited by TA in a ROS-dependent manner. ER stress is considered as one of the mechanisms contributing to ROS-mediated cell apoptosis [20]. Our results also demonstrated that LPS-induced ROS modulated the ER stress in $\mathrm{H} 9 \mathrm{C} 2$ cells, suggesting that the ROS-mediated ER stress pathway may be one of the important mechanistic pathways modulating apoptosis in LPS-induced H9C2 cells. Taken together, TA prevented LPS-induced ROS-mediated ER stress, which may be responsible for the TA-regulated decrease in H9C2 cells apoptosis.

\section{Discussion}

The major findings of this study are that (a) the use of appropriate TA concentrations promoted the increase of cell viability in LPS-induced $\mathrm{H} 9 \mathrm{C} 2$ cells, (b) TA attenuated ROS, ER stress, and apoptosis in LPS-induced H9C2 cells, (c) suppression of ROS-mediated ER stress-related apoptosis in LPS-induced $\mathrm{H} 9 \mathrm{C} 2$ cells was strongly involved in the protective effects of TA. Collectively, our data demonstrated that TA protected against LPS-induced $\mathrm{H} 9 \mathrm{C} 2$ cells apoptosis for the first time. Additionally, we observed that TA reduced the overproduction of ROS, as well as the level of ER stress. 
Sepsis is a serious disease with extremely high mortality, similar to that of acute myocardial infarction $[36,37]$. SIMD was defined as asepsis-associated acute syndrome of cardiac dysfunction. As there is still no effective treatment strategy for SIMD, there is an urgent need to explore the effective remedies and innovative treatment options to combat SIMD. LPS, the major compontent of bacterial outer membrane, is considered the principal cause responsible for multiorgan failure in sepsis, including myocardial depression $[38,39]$. LPS-induced $\mathrm{H} 9 \mathrm{C} 2$ cells are often used in the study of septic cardiomyopathy. Several mechanisms have been proposed to explain the pathophysiology of SIMD, including the excessive generation of inflammatory cytokines [40], ROS [41], cell death (necrosis and apoptosis) [42], impairment of nitricoxide [43], over-activation of ERS [26] and transcriptional and comprised metabolic changes [44]. Therefore, anti-inflammatory agents, anti-apoptosis agents, and anti-oxidants could be promising drugs to ameliorate SIMD.

TA is a natural polyphenol which has been used to improve human health [45]. TA is reported to alleviate acute lung injury [46], cardiac hypertrophy [47], acute doxorubicin-induced cardiotoxicity [48], and isoproterenol-induced myocardial injury [32]. However, there are no reports on the effects of TA on LPSinduced cardiomyocytes injury. This study was firstly performed to evaluate the possible mechanisms of action underlying tannic acid-mediated prevention of cardiomyocyte $\mathrm{H} 9 \mathrm{C} 2$ cell injury. Our study showed that administration of TA at high doses (40 and $50 \mu \mathrm{M})$ induced cell injury (Fig. 1a), whereas doses of TA lower than $20 \mu \mathrm{M}$ (including $20 \mu \mathrm{M}$ ) were nontoxic to H9C2 cells. When investigating the protective effect of TA against LPS-induced cell injury, using the viability CCK8 assay, we observed the capacity of TA to protect $\mathrm{H} 9 \mathrm{C} 2$ cells from LPS-induced cell injury in a dose-dependent manner (Fig. 1b).

ROS is well-known to trigger apoptosis through activation of essential stress signaling molecules, including c-Jun N-terminal kinase (JNK) [49, 50]. Moreover, the mitochondrion is a cause of ROS. Mitochondrial dysfunction is reportedly associated with cytochrome c release and the loss of mitochondrial membrane potential, ultimately resulting in increased apoptosis [51]. ROS is a key initiation factor for oxidative stress; excessive ROS increases in the body can induce oxidative stress [52, 53]. Many studies have shown that oxidative stress plays an important role in sepsis pathogenesis [11, 54]. In our study, we also found that ROS was increased in LPS-induced H9C2 cells (Fig. 3). However, TA was able to significantly inhibit ROS and apoptosis in the LPS-induced H9C2 cells (Fig. 2-3). This firstly confirmed the potential antioxidant and anti-apoptotic function of TA in LPS-induced H9C2 cells.

In addition to the dangerous and rapid reactivity against cellular components, ROS is recognized as potential signaling molecules for initiating various cellular events [55]. Many studies have suggested that ER stress is often induced by increased ROS production within the myocardium [56,57], the overexpression of ROS may further result in the dysregulation of the ER, complex UPR signaling pathway and cell apoptosis. In our study, we also determined the close relationship between ROS and ER stress. We found that ROS-mediated ER stress-related apoptosis in LPS-induced H9C2 cells (Fig. 5).

ER stress is mediated by three known transmembrane sensor proteins, namely inositol requiring enzyme 1 (IRE1), activating transcription factor 6 (ATF6) and protein kinase-like endoplasmic reticulum kinase 
(PERK) [58]. ER stress-related CHOP, Caspase12, and /or JNK-dependent apoptotic signaling pathways can be activated by a severe stimulus, which in turn affects the expression of Bax/Bcl-2 and the activation of Caspase3 $[24,59]$. High expression of CHOP upregulates the cytoplasmic pro-apoptotic protein Bax, and the release of Cyt from the mitochondria, leading to the activation of Caspase3, Caspase 9 and the induction of cell apoptosis [60]. In our study, we also observed that ER stress was triggered after LPS administration, eventually resulting in $\mathrm{H} 9 \mathrm{C} 2$ cell injury. Additionally, we found that TA was able to significantly inhibit ER stress in the LPS-induced H9C2 cells (Fig. 4). There was no research on effect of TA on the link of ROS and ER stress-related apoptosis in LPS-induced H9C2 cells. Therefore, further investigation is needed to determine whether ER stress plays an important role in ROS-scavenging by TA to reduce cardiomyocyte $\mathrm{H} 9 \mathrm{C} 2$ cell injury. NAC, a well-known ROS scavenger, was utilized as a positive control to treat $\mathrm{H} 9 \mathrm{C} 2$ cells. In our experiments, LPS-induced $\mathrm{H} 9 \mathrm{C} 2$ cells were preincubated with TA and / or NAC. Our data demonstrated that inhibition of ROS significantly suppressed the expression of ER stress-associated functional proteins induced by LPS. However, the expression of ER stressassociated proteins couldn't be suppressed by TA in the presence of NAC (ROS inhibitors) in LPS-induced H9C2 cells (Fig. 5a-h). We also suggested that the inhibition of ROS significantly suppressed ER stress-associated apoptotic proteins, including JNK, Bax, Cyt, Caspase3, Caspase12 and Caspase9. Moreover, the expression of ER stress-associated apoptotic proteins couldn't be suppressed by TA in the presence of NAC in LPS-induced H9C2 cells (Fig. 5i-o). Our results demonstrated that ER stress activation and apoptosis activation were inhibited by TA partly in a ROS-dependent manner.

In conclusion, our study firstly demonstrated that TA may protect LPS-induced H9C2 cells against damage via the suppression of ROS-mediated ER stress-associated apoptosis, providing a comprehensive understanding of the mechanisms underlying the cardioprotective role of TA. Based on this, TA may be targeted as an efficient therapeutic drug for the treatment of SIMD to improve heart function. Although our study suggests that the ROS-mediated ER stress-associated apoptosis exerts important functions in LPS-induced $\mathrm{H} 9 \mathrm{C} 2$ cell injury model, there may be some differences in an in vivo context. H9C2 cells were originally derived from embryonic cardiac tissue; however, in vivo cardiac myocytes have more complex functions. To better understand the mechanisms involved in cardiac injury, additional studies are needed in the future to evaluate these findings, and to identify more specific mechanisms in vivo.

\section{Abbreviations}

TA, tannic acid; LPS, lipopolysaccharide; SIMD, sepsis-induced myocardial dysfunction; ROS, reactive oxygen species; ERS, endoplasmic reticulum stress; UPR, unfolded protein response; IRE1, inositol requiring enzyme 1; ATF6, activating transcription factor 6; PERK, protein kinase-like endoplasmic reticulum kinase; $\mathrm{XBP} 1 \mathrm{~s}$, spliced $\mathrm{X}$ box-binding protein 1; $\mathrm{CYT}$, cytochrome c; $\mathrm{CHOP}, \mathrm{C} / \mathrm{EBP}$-homologous protein; JNK, c-Jun N-terminal kinase; NAC, N-Acetylcysteine

\section{Declarations}


Acknowledgments

Not applicable.

Funding

This study was funded by National Natural Science Foundation of China (Grant numbers: 91439126).

Availability of data and materials

The datasets used and/or analyzed during the current study are available from the corresponding author on reasonable request.

Authors' contributions

YPY, YHL and XL conceived the study. YPY and XL designed the experiments. YPY, JQZ, HBG, RZW, JJL, XLL and XLN performed the experiments, and acquired and analyzed the data. YPY wrote the manuscript. All authors read and approved the final manuscript.

Ethics approval and consent to participate

Not applicable.

Patient consent for publication

Not applicable.

Competing interests

The authors declare that they have no competing interests.

\section{Author details}

${ }^{1}$ Department of Cardiology, Tangdu Hospital, Air Force Medical University, Xi'an 710038, Shaanxi, People's Republic of China. ${ }^{2}$ Department of Plastic Surgery, General Hospital of Chinese PLA, Beijing 100853, People's Republic of China.

\section{References}

1. Rocheteau P, Chatre L, Briand D, Mebarki M, Jouvion G, Bardon J, Crochemore C, Serrani P, Lecci PP, Latil $M$, et al. Sepsis induces long-term metabolic and mitochondrial muscle stem cell dysfunction amenable by mesenchymal stem cell therapy. Nat Commun. 2015;6:10145.

2. Paoli CJ, Reynolds MA, Sinha M, Gitlin M, Crouser E. Epidemiology and Costs of Sepsis in the United States-An Analysis Based on Timing of Diagnosis and Severity Level. Crit Care Med. 2018;46(12):1889-97. 
3. Iwashyna TJ, Cooke CR, Wunsch H, Kahn JM. Population burden of long-term survivorship after severe sepsis in older Americans. J Am Geriatr Soc. 2012;60(6):1070-7.

4. Barie PS. World Sepsis Day: September 13, 2012. Surg Infect (Larchmt). 2012;13(4):185-6.

5. Huang M, Cai S, Su J. The Pathogenesis of Sepsis and Potential Therapeutic Targets. Int J Mol Sci 2019, 20(21).

6. Gaieski DF, Edwards JM, Kallan MJ, Carr BG. Benchmarking the incidence and mortality of severe sepsis in the United States. Crit Care Med. 2013;41(5):1167-74.

7. Zhang T, Yan T, Du J, Wang S, Yang H. Apigenin attenuates heart injury in lipopolysaccharide-induced endotoxemic model by suppressing sphingosine kinase 1/sphingosine 1-phosphate signaling pathway. Chem Biol Interact. 2015;233:46-55.

8. Lambden S, Creagh-Brown BC, Hunt J, Summers C, Forni LG. Definitions and pathophysiology of vasoplegic shock. Crit Care. 2018;22(1):174.

9. Martin L, Derwall M, Al Zoubi S, Zechendorf E, Reuter DA, Thiemermann C, Schuerholz T. The Septic Heart: Current Understanding of Molecular Mechanisms and Clinical Implications. Chest. 2019;155(2):427-37.

10. Lv X, Wang H. Pathophysiology of sepsis-induced myocardial dysfunction. Mil Med Res. 2016;3:30.

11. Liu YC, Yu MM, Shou ST, Chai YF. Sepsis-Induced Cardiomyopathy: Mechanisms and Treatments. Front Immunol. 2017;8:1021.

12. Drosatos K, Lymperopoulos A, Kennel PJ, Pollak N, Schulze PC, Goldberg IJ. Pathophysiology of sepsis-related cardiac dysfunction: driven by inflammation, energy mismanagement, or both? Curr Heart Fail Rep. 2015;12(2):130-40.

13. Bai T, Hu X, Zheng Y, Wang S, Kong J, Cai L. Resveratrol protects against lipopolysaccharide-induced cardiac dysfunction by enhancing SERCA2a activity through promoting the phospholamban oligomerization. Am J Physiol Heart Circ Physiol. 2016;311(4):H1051-62.

14. Kakihana Y, Ito T, Nakahara M, Yamaguchi K, Yasuda T. Sepsis-induced myocardial dysfunction: pathophysiology and management. J Intensive Care. 2016;4:22.

15. Tan S, Long Z, Hou X, Lin Y, Xu J, You X, Wang T, Zhang Y. H(2) Protects Against LipopolysaccharideInduced Cardiac Dysfunction via Blocking TLR4-Mediated Cytokines Expression. Front Pharmacol. 2019;10:865.

16. Turdi S, Han X, Huff AF, Roe ND, Hu N, Gao F, Ren J. Cardiac-specific overexpression of catalase attenuates lipopolysaccharide-induced myocardial contractile dysfunction: role of autophagy. Free Radic Biol Med. 2012;53(6):1327-38.

17. Jiang W, Luo F, Lu Q, Liu J, Li P, Wang X, Fu Y, Hao K, Yan T, Ding X. The protective effect of Trillin LPS-induced acute lung injury by the regulations of inflammation and oxidative state. Chem Biol Interact. 2016;243:127-34.

18. Qi XF, Zheng L, Lee KJ, Kim DH, Kim CS, Cai DQ, Wu Z, Qin JW, Yu YH, Kim SK. HMG-CoA reductase inhibitors induce apoptosis of lymphoma cells by promoting ROS generation and regulating Akt, Erk 
and p38 signals via suppression of mevalonate pathway. Cell Death Dis. 2013;4:e518.

19. Ding W, Yang L, Zhang M, Gu Y. Reactive oxygen species-mediated endoplasmic reticulum stress contributes to aldosterone-induced apoptosis in tubular epithelial cells. Biochem Biophys Res Commun. 2012;418(3):451-6.

20. Liu ZW, Zhu HT, Chen KL, Dong X, Wei J, Qiu C, Xue JH. Protein kinase RNA-like endoplasmic reticulum kinase (PERK) signaling pathway plays a major role in reactive oxygen species (ROS)mediated endoplasmic reticulum stress-induced apoptosis in diabetic cardiomyopathy. Cardiovascular diabetology. 2013;12:158.

21. Li D, Cong Z, Yang C, Zhu X. Inhibition of LPS-induced Nox2 activation by VAS2870 protects alveolar epithelial cells through eliminating ROS and restoring tight junctions. Biochem Biophys Res Commun. 2020;524(3):575-81.

22. Li A, Song NJ, Riesenberg BP, Li Z. The Emerging Roles of Endoplasmic Reticulum Stress in Balancing Immunity and Tolerance in Health and Diseases: Mechanisms and Opportunities. Front Immunol. 2019;10:3154.

23. Oyadomari S, Yun C, Fisher EA, Kreglinger N, Kreibich G, Oyadomari M, Harding HP, Goodman AG, Harant $\mathrm{H}$, Garrison JL, et al. Cotranslocational degradation protects the stressed endoplasmic reticulum from protein overload. Cell. 2006;126(4):727-39.

24. Wang M, Kaufman RJ. Protein misfolding in the endoplasmic reticulum as a conduit to human disease. Nature. 2016;529(7586):326-35.

25. Liu L, Wu H, Zang J, Yang G, Zhu Y, Wu Y, Chen X, Lan D, Li T. 4-Phenylbutyric Acid Reveals Good Beneficial Effects on Vital Organ Function via Anti-Endoplasmic Reticulum Stress in Septic Rats. Crit Care Med. 2016;44(8):e689-701.

26. Khan MM, Yang WL, Wang P. Endoplasmic Reticulum Stress in Sepsis. Shock. 2015;44(4):294-304.

27. Salminen J-P, Karonen M. Chemical ecology of tannins and other phenolics: we need a change in approach. Funct Ecol. 2011;25(2):325-38.

28. Darvin P, Joung YH, Kang DY, Sp N, Byun HJ, Hwang TS, Sasidharakurup H, Lee CH, Cho KH, Park KD, et al. Tannic acid inhibits EGFR/STAT1/3 and enhances p38/STAT1 signalling axis in breast cancer cells. J Cell Mol Med. 2017;21(4):720-34.

29. Pattarayan D, Sivanantham A, Krishnaswami V, Loganathan L, Palanichamy R, Natesan S, Muthusamy K, Rajasekaran S. Tannic acid attenuates TGF- $\beta 1$-induced epithelial-to-mesenchymal transition by effectively intervening TGF- $\beta$ signaling in lung epithelial cells. J Cell Physiol. 2018;233(3):2513-25.

30. Pattarayan D, Sivanantham A, Bethunaickan R, Palanichamy R, Rajasekaran S. Tannic acid modulates fibroblast proliferation and differentiation in response to pro-fibrotic stimuli. J Cell Biochem. 2018;119(8):6732-42.

31. Sivanantham A, Pattarayan D, Bethunaickan R, Kar A, Mahapatra SK, Thimmulappa RK, Palanichamy R, Rajasekaran S. Tannic acid protects against experimental acute lung injury through downregulation of TLR4 and MAPK. J Cell Physiol. 2019;234(5):6463-76. 
32. Hu X, Wang H, Lv X, Chu L, Liu Z, Wei X, Chen Q, Zhu L, Cui W. Cardioprotective Effects of Tannic Acid on Isoproterenol-Induced Myocardial Injury in Rats: Further Insight into 'French Paradox'. Phytother Res. 2015;29(9):1295-303.

33. Shan P, Pu J, Yuan A, Shen L, Shen L, Chai D, He B. RXR agonists inhibit oxidative stress-induced apoptosis in H9c2 rat ventricular cells. Biochem Biophys Res Commun. 2008;375(4):628-33.

34. Lei Y, Yang Y, Zhao J, Gao H, Chen R, Bai B, Kang X, He Y, Ding L, Wei T, et al. P-AKT2/SPK1 (P-SPK1) and $\mathrm{P}-\mathrm{MEK} / \mathrm{P}-\mathrm{ERK}$ cell signaling pathways are involved in LPS-induced macrophage migration. American journal of translational research. 2019;11(5):2725-41.

35. Zhao J, Lei Y, Yang Y, Gao H, Gai Z, Li X. Metoprolol alleviates arginine vasopressin-induced cardiomyocyte hypertrophy by upregulating the AKT1-SERCA2 cascade in H9C2 cells. Cell Biosci. 2020;10:72.

36. Kotfis K, Wittebole X, Jaschinski U, Solé-Violán J, Kashyap R, Leone M, Nanchal R, Fontes LE, Sakr Y, Vincent JL. A worldwide perspective of sepsis epidemiology and survival according to age:

Observational data from the ICON audit. J Crit Care. 2019;51:122-32.

37. Keeley A, Hine P, Nsutebu E. The recognition and management of sepsis and septic shock: a guide for non-intensivists. Postgraduate medical journal. 2017;93(1104):626-34.

38. Opal SM, Scannon PJ, Vincent JL, White M, Carroll SF, Palardy JE, Parejo NA, Pribble JP, Lemke JH. Relationship between plasma levels of lipopolysaccharide (LPS) and LPS-binding protein in patients with severe sepsis and septic shock. The Journal of infectious diseases. 1999;180(5):1584-9.

39. Li Y, Ge S, Peng Y, Chen X. Inflammation and cardiac dysfunction during sepsis, muscular dystrophy, and myocarditis. Burns trauma. 2013;1(3):109-21.

40. Hu D, Yang X, Xiang Y, Li H, Yan H, Zhou J, Caudle Y, Zhang X, Yin D. Inhibition of Toll-like receptor 9 attenuates sepsis-induced mortality through suppressing excessive inflammatory response. Cellular immunology. 2015;295(2):92-8.

41. Lowes DA, Webster NR, Murphy MP, Galley HF. Antioxidants that protect mitochondria reduce interleukin- 6 and oxidative stress, improve mitochondrial function, and reduce biochemical markers of organ dysfunction in a rat model of acute sepsis. Br J Anaesth. 2013;110(3):472-80.

42. Zhang Y, Xu X, Ceylan-Isik AF, Dong M, Pei Z, Li Y, Ren J. Ablation of Akt2 protects against lipopolysaccharide-induced cardiac dysfunction: role of Akt ubiquitination E3 ligase TRAF6. J Mol Cell Cardiol. 2014;74:76-87.

43. Luiking YC, Poeze M, Deutz NE: Arginine infusion in patients with septic shock increases nitric oxide production without haemodynamic instability. Clinical science (London, England: 1979) 2015, 128(1):57-67.

44. Wilson J, Higgins D, Hutting H, Serkova N, Baird C, Khailova L, Queensland K, Vu Tran Z, Weitzel L, Wischmeyer PE. Early propranolol treatment induces lung heme-oxygenase-1, attenuates metabolic dysfunction, and improves survival following experimental sepsis. Crit Care. 2013;17(5):R195.

45. Nie F, Liang Y, Jiang B, Li X, Xun H, He W, Lau HT, Ma X. Apoptotic effect of tannic acid on fatty acid synthase over-expressed human breast cancer cells. Tumour Biol. 2016;37(2):2137-43. 
46. Zhang T, Zhang R, Dang M, Qiu S, Gu H, He P, Guo G. Ameliorative effects of tannic acid on lipopolysaccharide-induced sepsis and acute lung injury in mice. Pharmacognosy Magazine 2019, 15(61).

47. Chu L, Li P, Song T, Han X, Zhang X, Song Q, Liu T, Zhang Y, Zhang J. Protective effects of tannic acid on pressure overload-induced cardiac hypertrophy and underlying mechanisms in rats. J Pharm Pharmacol. 2017;69(9):1191-207.

48. Zhang J, Cui L, Han X, Zhang Y, Zhang X, Chu X, Zhang F, Zhang Y, Chu L. Protective effects of tannic acid on acute doxorubicin-induced cardiotoxicity: Involvement of suppression in oxidative stress, inflammation, and apoptosis. Biomed Pharmacother. 2017;93:1253-60.

49. Fiers W, Beyaert R, Declercq W, Vandenabeele P. More than one way to die: apoptosis, necrosis and reactive oxygen damage. Oncogene. 1999;18(54):7719-30.

50. Sakon S, Xue X, Takekawa M, Sasazuki T, Okazaki T, Kojima Y, Piao JH, Yagita H, Okumura K, Doi T, et al. NF-kappaB inhibits TNF-induced accumulation of ROS that mediate prolonged MAPK activation and necrotic cell death. EMBO J. 2003;22(15):3898-909.

51. Quoilin C, Mouithys-Mickalad A, Lecart S, Fontaine-Aupart MP, Hoebeke M. Evidence of oxidative stress and mitochondrial respiratory chain dysfunction in an in vitro model of sepsis-induced kidney injury. Biochim Biophys Acta. 2014;1837(10):1790-800.

52. Wible DJ, Bratton SB. Reciprocity in ROS and autophagic signaling. Curr Opin Toxicol. 2018;7:28-36.

53. Bardaweel SK, Gul M, Alzweiri M, Ishaqat A, HA AL, Bashatwah RM. Reactive Oxygen Species: the Dual Role in Physiological and Pathological Conditions of the Human Body. Eurasian J Med. 2018;50(3):193-201.

54. L'Heureux M, Sternberg M, Brath L, Turlington J, Kashiouris MG. Sepsis-Induced Cardiomyopathy: a Comprehensive Review. Curr Cardiol Rep. 2020;22(5):35.

55. Prauchner CA. Oxidative stress in sepsis: Pathophysiological implications justifying antioxidant cotherapy. Burns. 2017;43(3):471-85.

56. Xu Y, Liu P, Xu S, Koroleva M, Zhang S, Si S, Jin ZG. Tannic acid as a plant-derived polyphenol exerts vasoprotection via enhancing KLF2 expression in endothelial cells. Scientific Reports 2017, 7(1).

57. Li YH, Zhang WL, Zhou HY, Yu DW, Sun XN, Hu Q. Halofuginone protects against advanced glycation end productsinduced injury of $\mathrm{H} 9 \mathrm{C} 2$ cells via alleviating endoplasmic reticulum stressassociated apoptosis and inducing autophagy. Mol Med Rep. 2019;20(4):3131-9.

58. Cheng YC, Chen CA, Chen HC. Endoplasmic reticulum stress-induced cell death in podocytes. Nephrology (Carlton). 2017;22(Suppl 4):43-9.

59. Tabas I, Ron D. Integrating the mechanisms of apoptosis induced by endoplasmic reticulum stress. Nat Cell Biol. 2011;13(3):184-90.

60. Yang J, Wu Q, Lv J, Nie H. 4-Phenyl butyric acid prevents glucocorticoid-induced osteoblast apoptosis by attenuating endoplasmic reticulum stress. J Bone Miner Metab. 2016;35(4):366-74. 


\section{Tables}

\section{Table 1}

Primers used for real-time qPCR analyses in this study

\begin{tabular}{|c|c|c|}
\hline Target genes & \multicolumn{2}{|c|}{ Primer sequences } \\
\hline \multicolumn{3}{|l|}{ Rat } \\
\hline \multirow[t]{2}{*}{ Gapdh } & Forward & 5'-ACAGCAACAGGGTGGTGGAC-3' \\
\hline & Reverse & 5'-TTTGAGGGTGCAGCGAACTT-3' \\
\hline \multirow[t]{2}{*}{ Atf6 } & Forward & 5'-GAACTTCGAGGCTGGGTTCA-3' \\
\hline & Reverse & 5'-AACTTCCAGGCGAAGCGTAA-3' \\
\hline \multirow[t]{2}{*}{ Xbp1s } & Forward & 5'-GTGTCTAAAGCCACCCACCA-3' \\
\hline & Reverse & 5'-ACCTTTGAAGACCTCAGACAGC-3' \\
\hline \multirow[t]{2}{*}{ Chop } & Forward & 5'-GCTCAAGCAGGAAATCGAGC-3' \\
\hline & Reverse & 5'-CAAGCCССTCTCCTTTGGTC-3' \\
\hline \multirow[t]{2}{*}{ Bax } & Forward & 5'-TGGGATGGCCTCCTTTCCTA-3' \\
\hline & Reverse & 5'-TTCCCCGTTCCCCATTCATC-3' \\
\hline \multirow[t]{2}{*}{ Cyt } & Forward & 5'-ATGCTGCCTTTCACCACTGA-3' \\
\hline & Reverse & 5'-GTACCACTCCCAATCAGGCA-3' \\
\hline \multirow[t]{2}{*}{ Caspase 3} & Forward & 5'-ACTGGAATGTCAGCTCGCAA-3' \\
\hline & Reverse & 5'-TTTTCAGGTCCACAGGTCCG-3' \\
\hline \multirow[t]{2}{*}{ Caspase 12} & Forward & 5'-GTTTGGCCAAGGACATGCTG-3' \\
\hline & Reverse & 5'-GCTGTTTGTCGGAATTGGCA-3' \\
\hline \multirow[t]{2}{*}{ Perk } & Forward & 5'-CTTTCGGTGCTCCAAGGCTC-3' \\
\hline & Reverse & 5'-CGTATCCGATGTGGGAGCAA-3' \\
\hline \multirow[t]{2}{*}{ Ire1 } & Forward & 5'-ATGGGTGGCGTTCATCATCA-3' \\
\hline & Reverse & 5'-AGGGTCCTGGGTAAGGTCTC-3' \\
\hline
\end{tabular}


$\mathbf{a}$

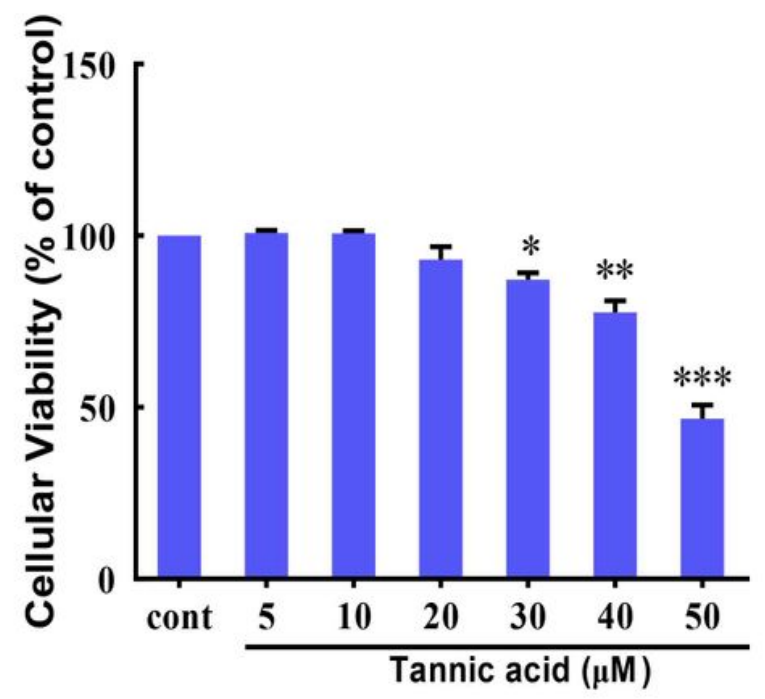

b

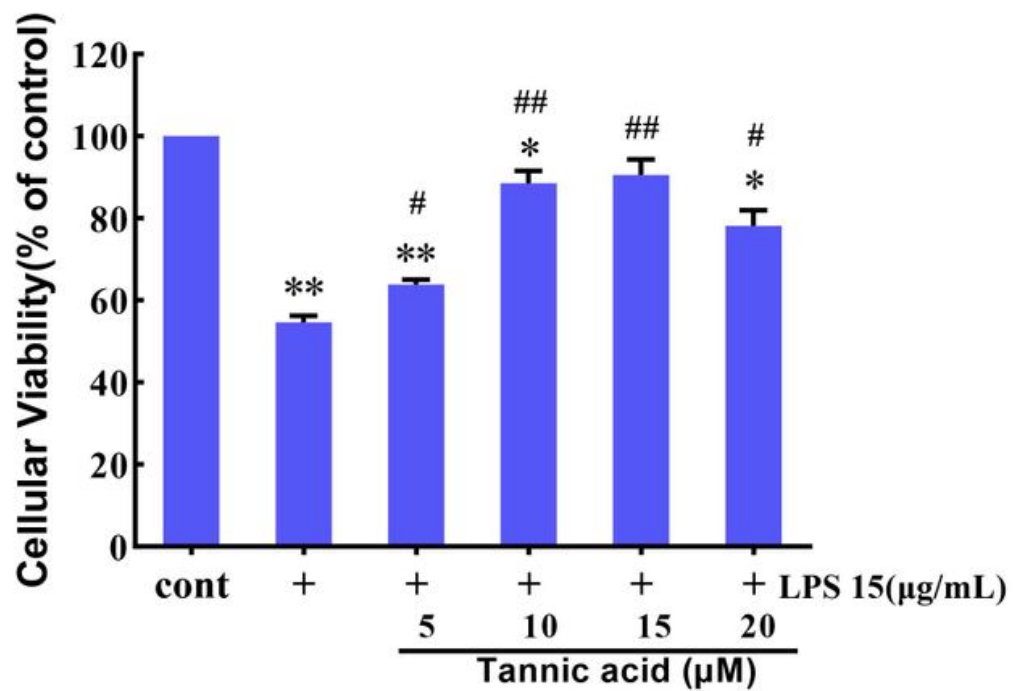

Figure 1

Effect of TA on H9C2cell viability. Cell viability was determined using the CCK-8 assay. a Cell viability of $\mathrm{H} 9 \mathrm{C} 2$ cells treated with varying concentrations of $\operatorname{TA}(0,5,10,20,30,40$, and $50 \mu \mathrm{M})$ for $24 \mathrm{~h}$. b Cell viability of $\mathrm{H} 9 \mathrm{C} 2$ cells pretreated with a series concentration of $\operatorname{TA}(0,5,10$ and $20 \mu \mathrm{M})$ for $2 \mathrm{~h}$, and then treated with $15 \mu \mathrm{g} / \mathrm{mL}$ of LPS for a further $24 \mathrm{~h}$. Data were presented as mean \pm SEM $(n=3$, three independent experiments were performed). Statistical significance is defined as ${ }^{*} p<0.05,{ }^{*} p<0.01$ and $\star * \star p<0.001$ vs. cont; \#p $<0.05$ and \#\#p $<0.01$ vs. LPS alone group. TA, tannic acid; LPS, lipopolysaccharide; cont, control. 
a

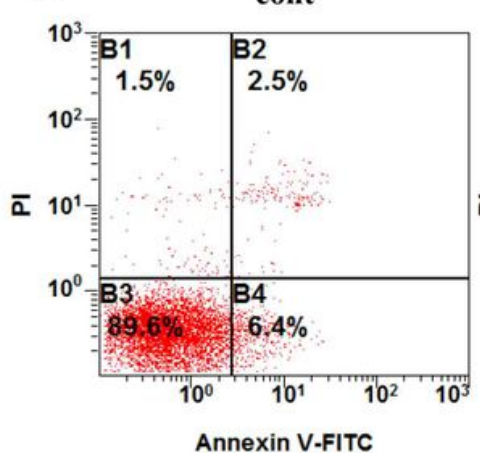

b

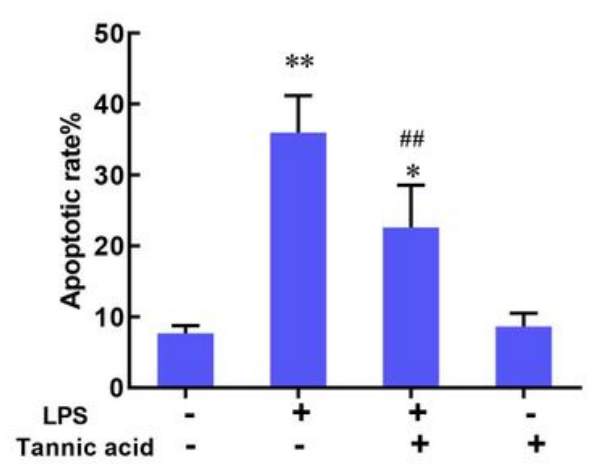

LPS

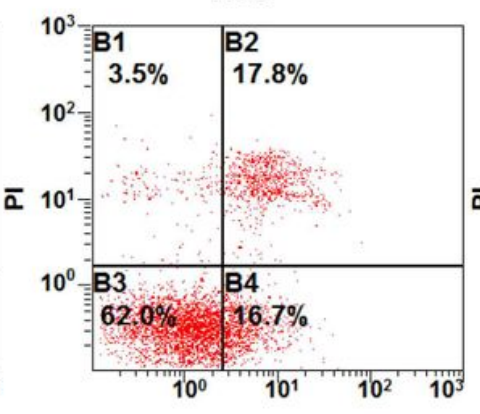

Annexin V-FITC

C

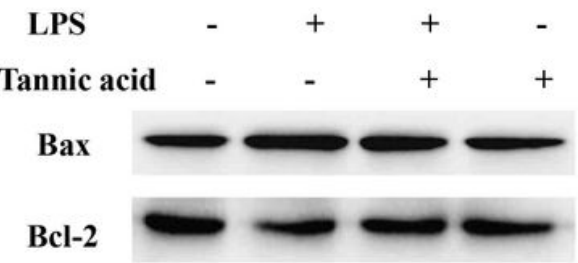

TA+LPS

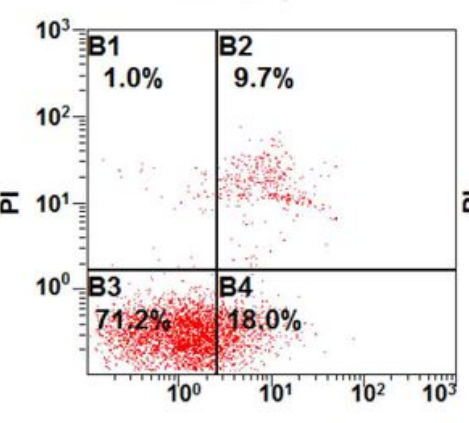

Annexin V-FITC
TA

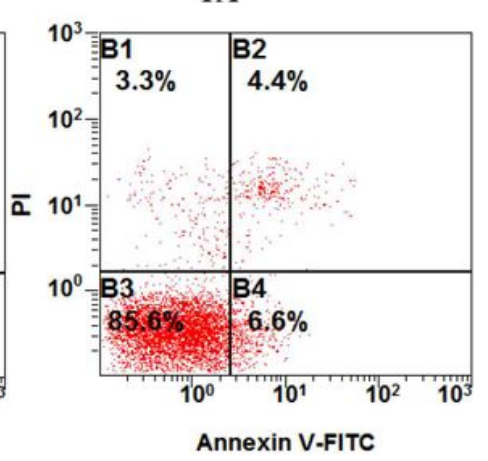

d

Cleaved

Caspase 9

Cleaved

Caspase 3

$\beta$-actin

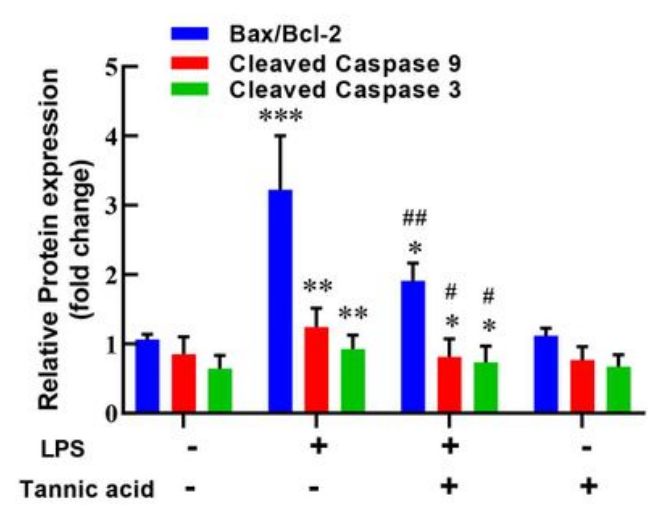

Figure 2

TA alleviates LPS-induced apoptosis in $\mathrm{H} 9 \mathrm{C} 2$ cells. a Flow cytometry was used to determine cell apoptosis rate using AnnexinV FITC/PI staining. Apoptotic cells included Annexin V (+)/PI (-) and Annexin V (+)/PI (+) cells. b Quantitative analysis of the apoptotic cells was performed with LPS, TA and TA+LPS treatments. $c$ The protein expression of Bax, Bcl-2, Cleaved Caspase9,Cleaved Caspase 3 and $\beta$ actin in $\mathrm{H} 9 \mathrm{C} 2$ cells treated with LPS, TA or TA+LPS were determined by western blot analysis. $d$ Quantification of the protein expression of Bax/Bcl-2, Cleaved Caspase9,Cleaved Caspase 3 in the LPS, TA and TA+LPS treated H9C2 cells. Data were presented as mean \pm SEM of three independent experiments $(n=3)$. Statistical significance is defined as $* p<0.05$ and $* * p<0.01$ and $* \star * p<0.001$ vs. cont; $\# p<0.05$ and \#\#p $<0.01$ vs. LPS alone group. TA, tannic acid; LPS, lipopolysaccharide; cont, control. 
$\mathbf{a}$
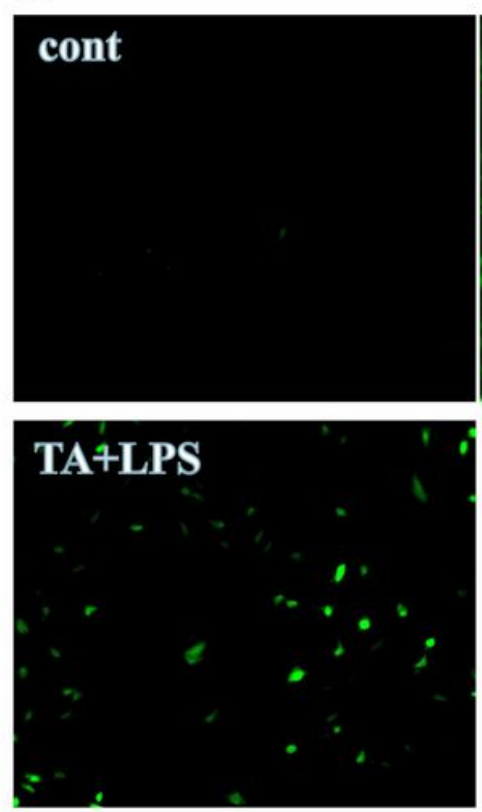

b

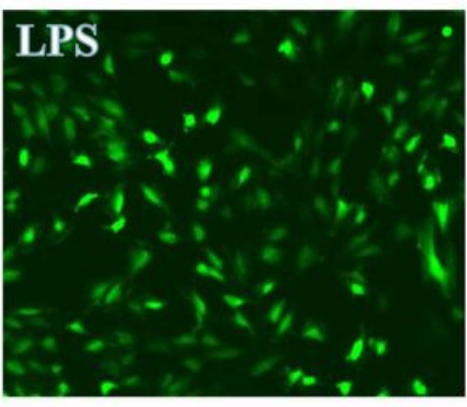

\section{TA}

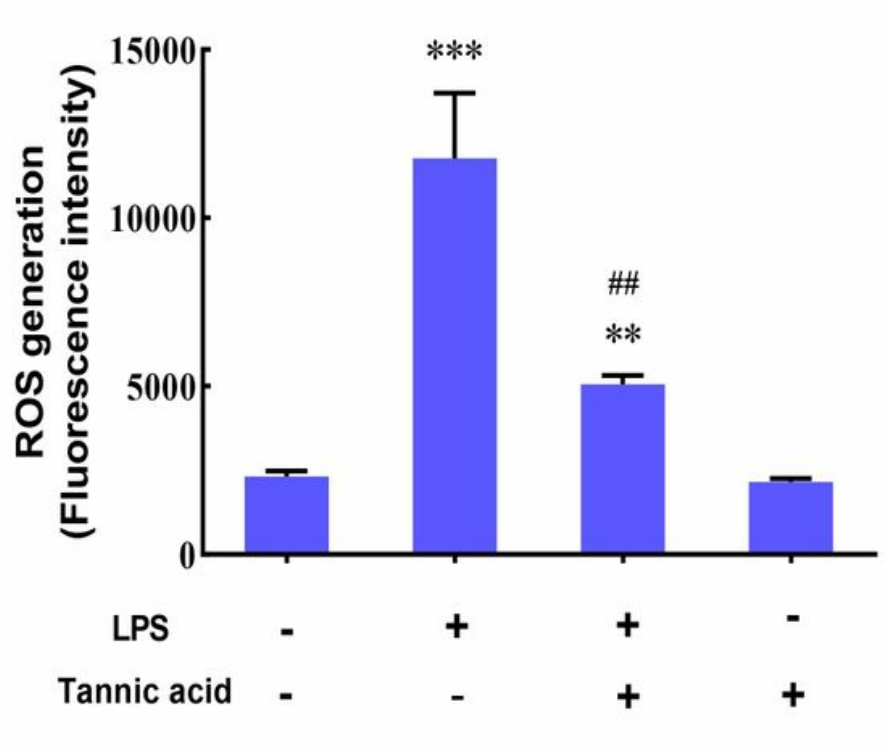

\section{Figure 3}

TA attenuates ROS production in LPS-induced $\mathrm{H} 9 \mathrm{C} 2$ cells. Data represents ROS fluorescence intensity using the DCFH-DA assay. a Laser confocal microscopy measurement of cellular ROS production by H9C2 cells treated with LPS, TA and TA+LPS (scale bar $=100 \mu \mathrm{m}$ ) b Quantitative analysis of the mean fluorescence intensity following treatment with LPS, TA and TA+LPS. Data is presented as mean \pm SEM of at least three independent experiments. Statistical significance is defined as ${ }^{*} p<0.05$ and ${ }^{* *} p<0.01$ and ${ }^{* \star} p<0.001$ vs. cont; $\# p<0.05$ and \#\#p $<0.01$ vs. LPS alone group. ROS, reactive oxygen species; TA, tannic acid; LPS, lipopolysaccharide; cont, control. 
$\mathbf{a}$

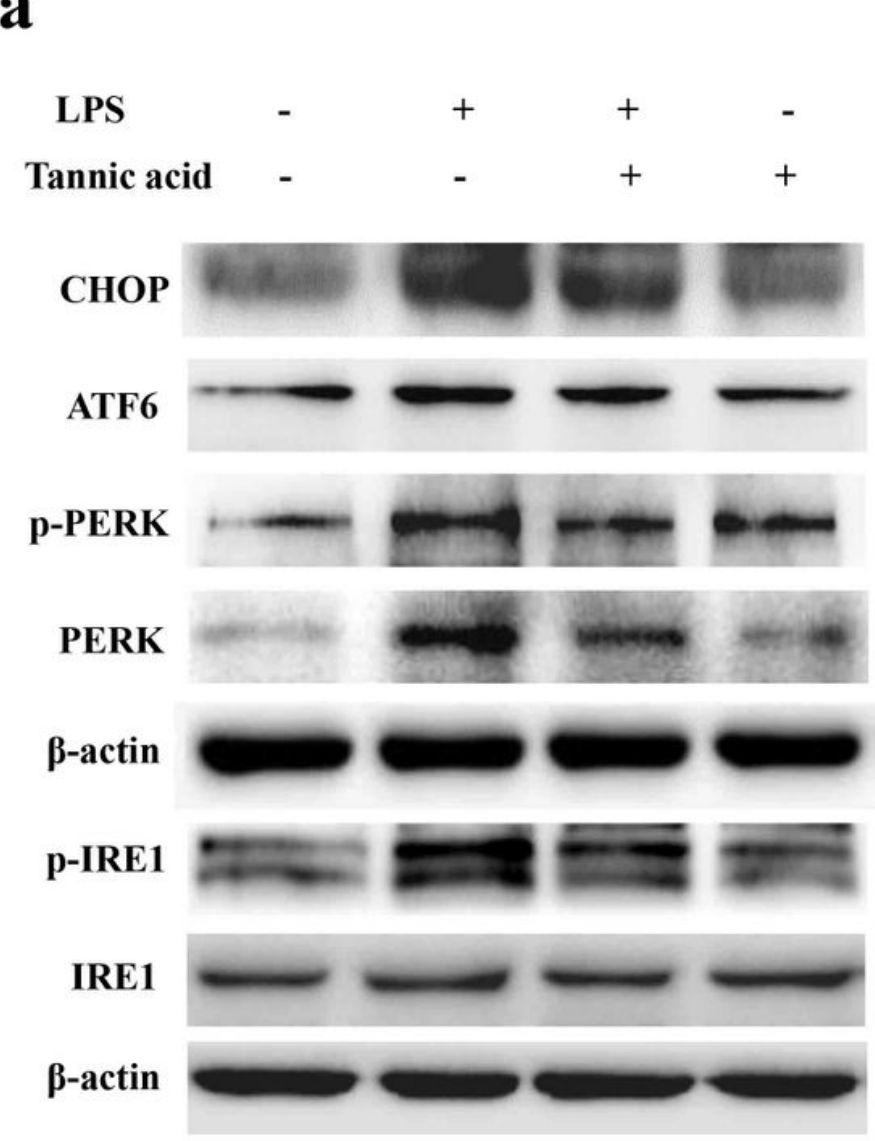

b

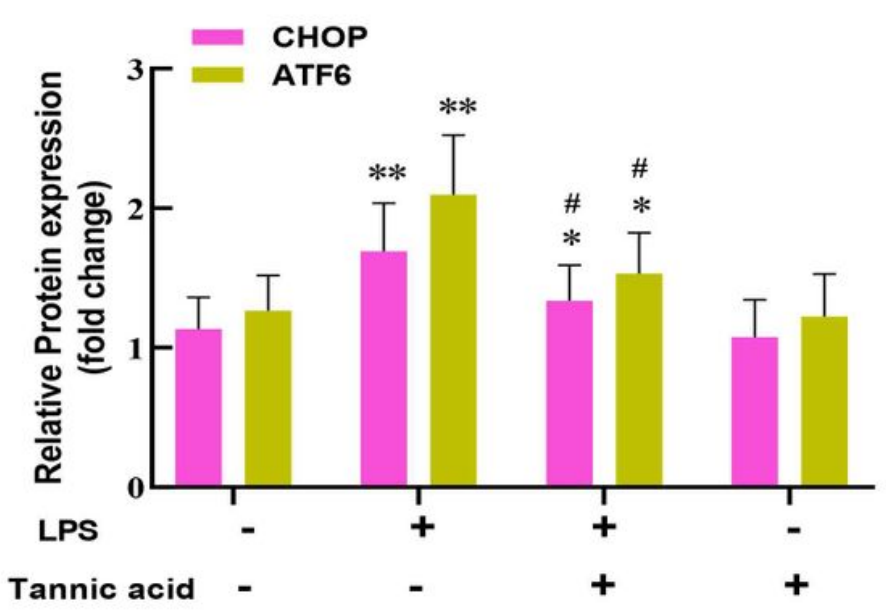

C

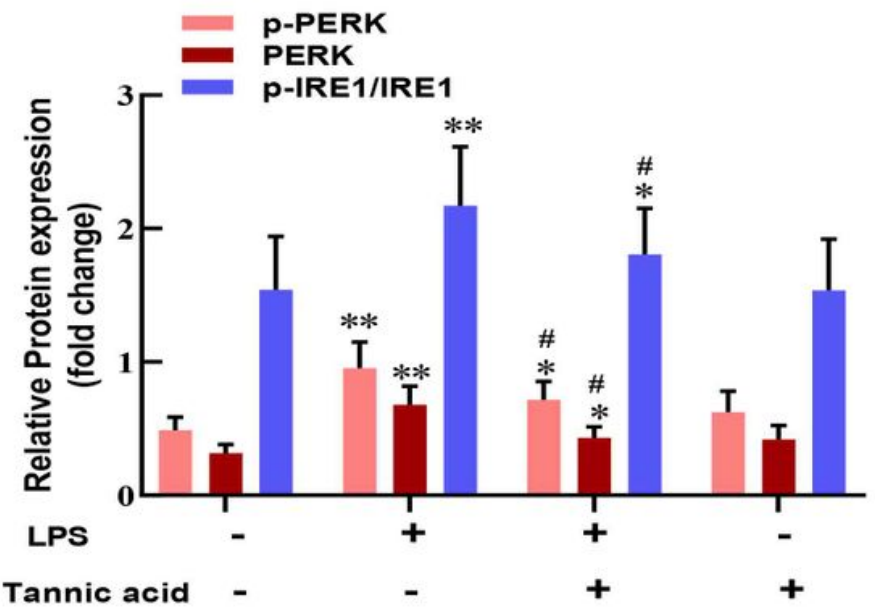

\section{Figure 4}

TA alleviates LPS-induced ER stress in H9C2 cells. a The protein expression of CHOP, ATF6, PhosphoPERK, PERK, Phospho-IRE1, IRE1 and $\beta$-actin in H9C2 cells treated with LPS, TA and TA+LPS as determined by western blot analysis. $b$ and $c$ Protein expression quantification of CHOP, ATF6, PhosphoPERK, PERK, Phospho-IRE1/IRE1 in the LPS, TA and TA+LPS treated H9C2 cells. Data were presented as mean \pm SEM of three independent experiments $(n=3)$. Statistical significance is defined as ${ }^{*} p<0.05$, $* * p$ $<0.01$ and ${ }^{* * *} p<0.001$ vs. cont; $\# p<0.05$ and \#\#p $<0.01$ vs. LPS alone group. ERS, endoplasmic reticulum stress; TA, tannic acid; LPS, lipopolysaccharide; cont, control. 


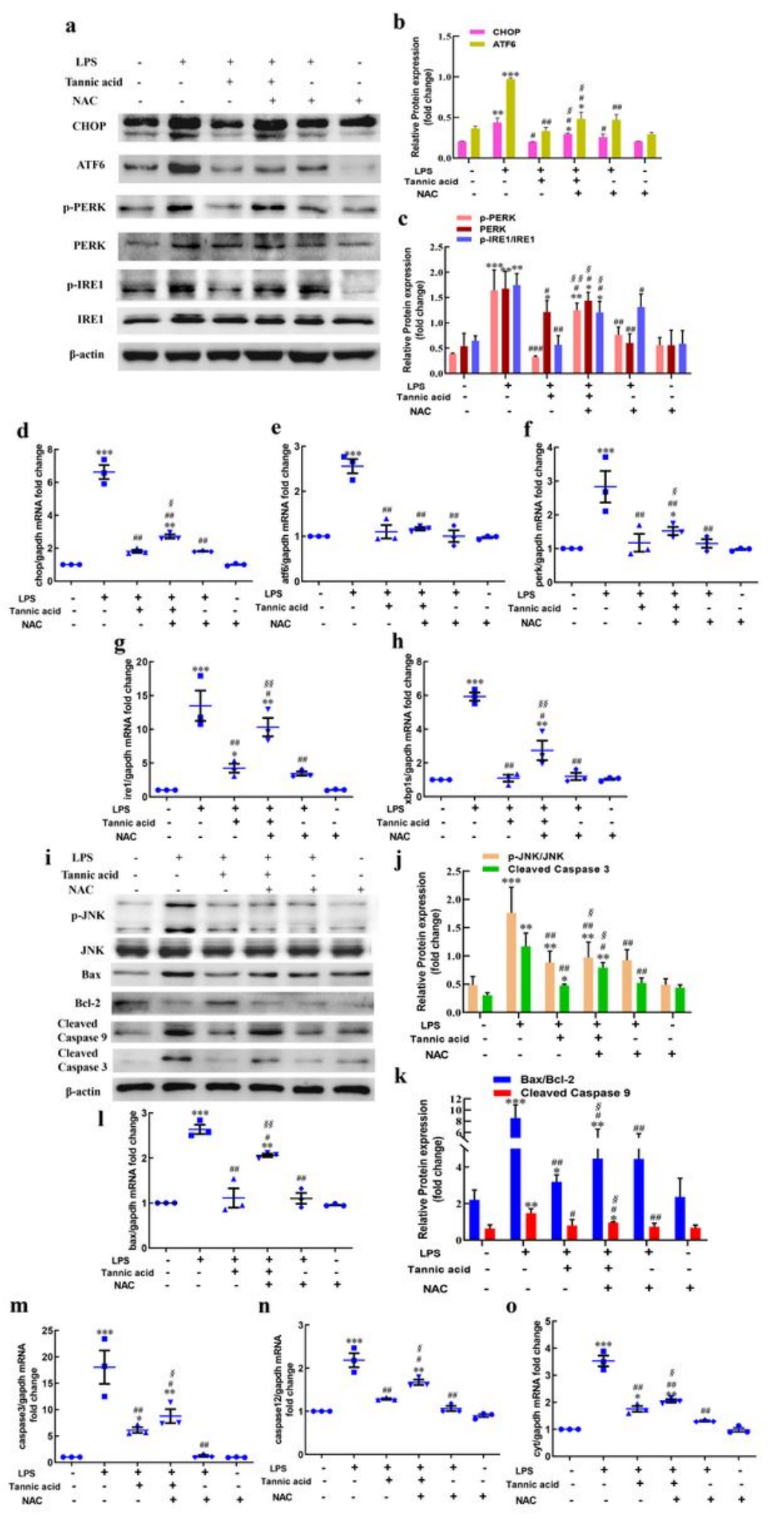

Figure 5

TA attenuated LPS-induced apoptosis via suppressing ROS-mediated ER stress in H9C2 cells. a Protein expression in LPS stimulated $\mathrm{H} 9 \mathrm{C} 2$ cells. Whole cell lysates were prepared following stimulation with LPS, NAC, and TA. The protein expression of CHOP, ATF6, Phospho-PERK, PERK, Phospho-IRE1/IRE1 in H9C2 cells treated with LPS, NAC+LPS, TA+LPS and TA+NAC+LPS were determined by western blot analysis. b and c Protein expression quantification of CHOP, ATF6, Phospho-PERK, PERK, Phospho- 
IRE1/IRE1 in H9C2 cells. d-h mRNA expression in H9C2 cells. Graph shows Gapdh normalized levels of Chop, Atf6, Perk, Ire1, Xbp1s. i Protein expression levels of apoptosis-associated proteins (p-JNK, JNK, Bax, Cleaved Caspase9, and Cleaved Caspase3) and anti-apoptosis protein (Bcl-2) were analyzed by western blotting. j and k Protein expression quantification of Phospho-JNK/JNK, Cleaved Caspase 3, Bax/Bcl-2, Cleaved Caspase 9 in H9C2 cells. I-o The mRNA expression in H9C2 cells. Graph shows Gapdh normalized levels of Bax, Caspase 3, Cyt, Caspase 12. Data were presented as mean \pm SEM of three independent experiments $(n=3)$. Statistical significance is defined as ${ }^{*} p<0.05$, ${ }^{*} p<0.01$ and $* \star \star p<<$ $0.001 v$ s. cont; $\# p<0.05$ and \#\#p $<0.01$ vs. LPS alone group; $\S p<0.05$, $\S \S p<0.01$ vs. TA+LPS. NAC, NAcetylcysteine; ERS, endoplasmic reticulum stress; TA, tannic acid; LPS, lipopolysaccharide; cont, control. 